\title{
EVALUATION OF NATURAL SLOPE FAILURES INDUCED BY THE 2004 NIIGATA-KEN CHUETSU EARTHQUAKE
}

\author{
Hirofumi Toyota ${ }^{\mathrm{i})}$, JinXING WANG ${ }^{\mathrm{ii})}$, KoulchI NAKAmura ${ }^{\mathrm{iii})}$ and NAOKI SAKai ${ }^{\mathrm{iv})}$
}

\begin{abstract}
Slope failures occurring near earthquake centres have attracted much attention since the 2004 Niigata-ken Chuetsu Earthquake. The 1995 Hyogoken-nambu Earthquake affected large modern cities and urban infrastructure, but hilly and mountainous areas suffered heavy damage from the Niigata-ken Chuetsu Earthquake. During that earthquake, numerous landslides occurred in Koshi of Nagaoka city (formerly Yamakoshi village). Social problems developed when many towns became isolated because landslides cut off traffic and public service lifelines. Soil from landslides closed river channels and formed natural dams along the Imo River, which flows north to south in Koshi. The natural dams submerged some towns and emergency measures were promptly undertaken to prevent debris flows caused by natural dam breaks. In addition, many surface slides also occurred at steep slopes. The endogenous and exogenous factors of those landslides must be clarified because of their few precedents. For that purpose, topography and geology in this region are arranged according to each failure type. In addition, triaxial tests of saturated and unsaturated soils obtained from a slope failure site were conducted to examine the soils' strength properties. This research is intended to propose estimation items that can help to judge the risk of natural slope failure.
\end{abstract}

Key words: earthquake damage, geology, site investigation, topography, triaxial test, unsaturated soil (IGC: B11/D6)

\section{INTRODUCTION}

At 17:56 on 23 October 2004, the Niigata-ken Chuetsu Earthquake, whose main tremor was magnitude 6.8, struck central Niigata-ken (Chuetsu area) and seriously damaged infrastructures of hilly and mountainous areas including Kawaguchi town, Ojiya city, Nagaoka city, and their environs (Fig. 1). The earthquake was an epicentral thrust-fault earthquake with a hypocentre of about $10 \mathrm{~km}$ depth, with characteristic frequent strong aftershocks that engendered increased damage.

In the Chuetsu area, thick alluvium covers plains; hilly areas are composed mainly of soft mudstone of quaternary and tertiary deposits. Quaternary deposits are new strata formed from two million years ago. Tertiary deposits are geological structures formed between 24 million and 2 million years ago. The geomorphology formed by folding presents a prominent landslide area in this region. The region exhibits catchment area dotted with many ponds and rice terraces. In addition, rainfall of more than $100 \mathrm{~mm}$ was recorded from typhoon No. 23, which passed through the Chuetsu area two days before the earthquake. Daily rainfall of 21 October 2004 at Nagaoka city, based on data from the Japan Meteorol-

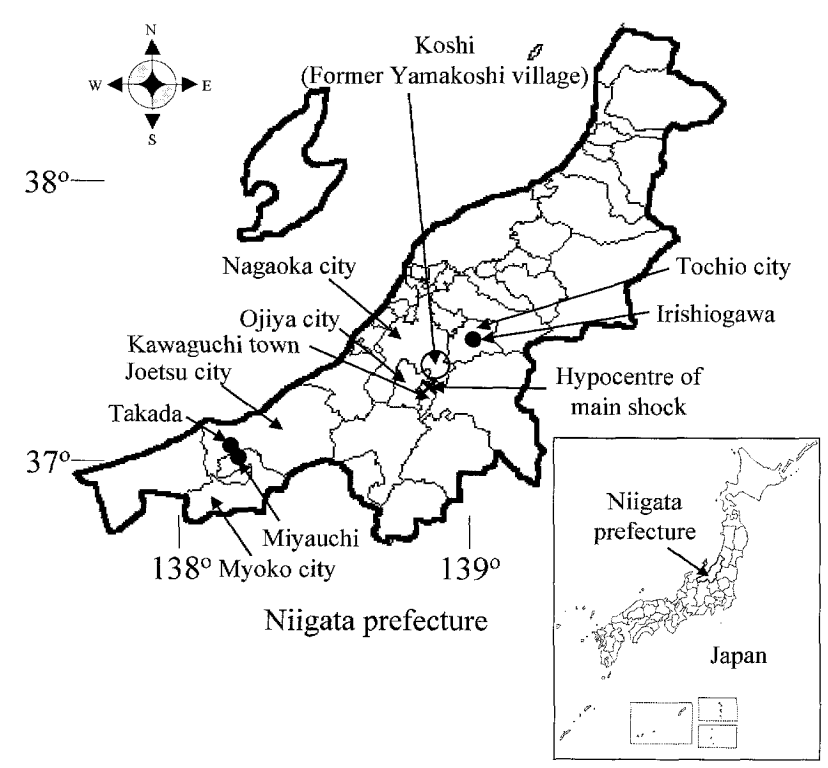

Fig. 1. Map of Niigata prefecture

ogical Agency, reached $115 \mathrm{~mm}$. Under those circumstances, more than 3,000 landslides occurred in the hilly area close to the seismic centre during the earthquake.

i) Associate Professor, Department of Civil and Environmental Engineering, Nagaoka University of Technology, Japan (toyota@) vos.nagaokaut.ac.jp).

ii) Graduate Student, ditto.

iii) Postdoctoral Fellowship of JSPS, Japan.

iv) Researcher, Public Works Research Institute, Japan.

The manuscript for this paper was received for review on May 9, 2006; approved on October 2, 2006.

Written discussions on this paper should be submitted before July 1, 2007 to the Japanese Geotechnical Society, 4-38-2, Sengoku, Bunkyo-ku, Tokyo 112-0011, Japan. Upon request the closing date may be extended one month. 


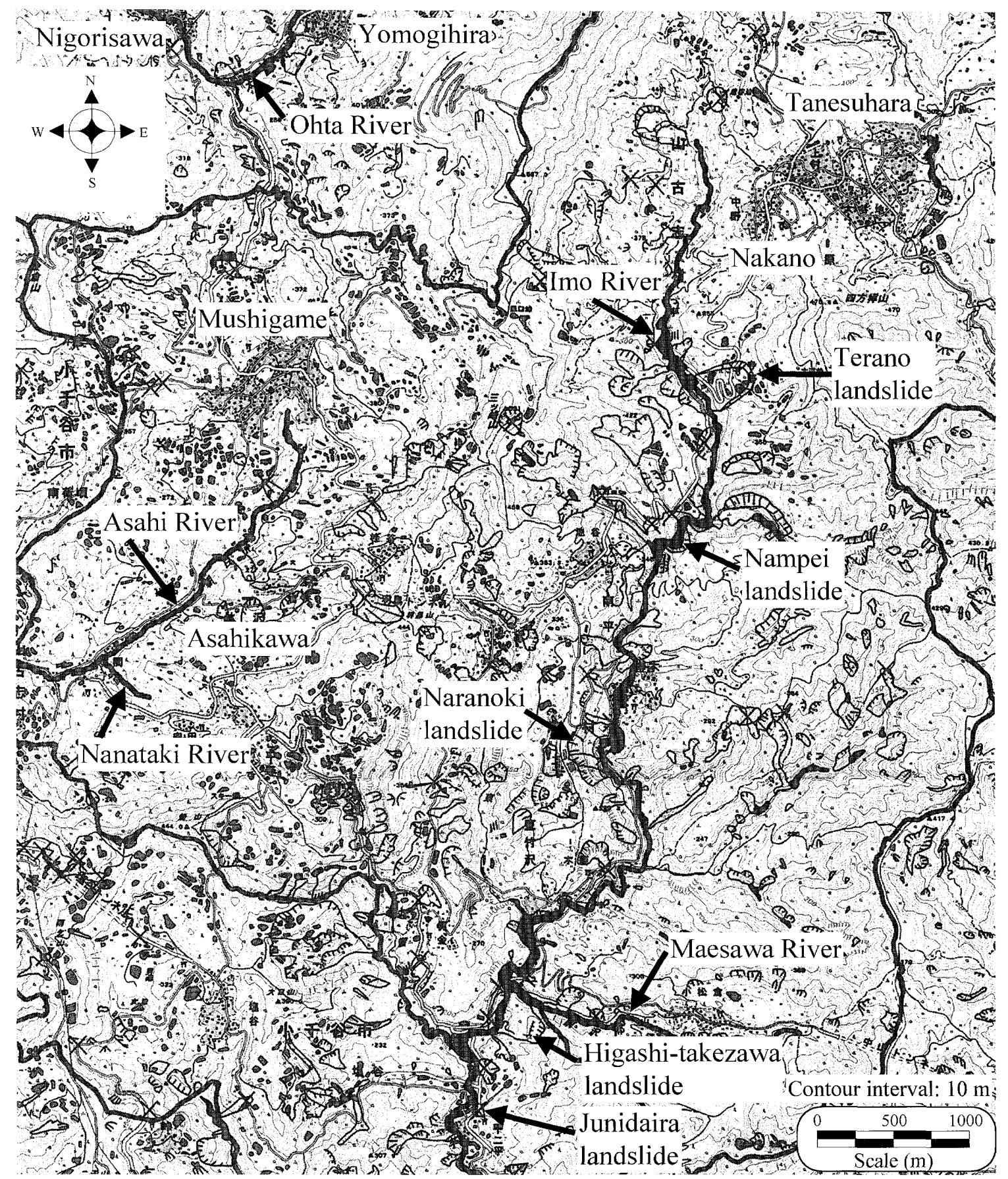

Fig. 2. Disaster map around Koshi of Nagaoka city (provided by Geographical Survey Institute)

Their specific damage information was reported by the Japan Society of Civil Engineers (2006).

The present paper describes topographical and geological characteristics of the landslide area caused by the earthquake. In addition, monotonic and cyclic triaxial tests were conducted using undisturbed and reconstituted samples obtained from a slope failure point to elucidate mechanical properties of saturated and unsaturated soil.

\section{OLD LANDSLIDES IN THE KOSHI AREA}

"Tanesuhara", "Mushigame" and "Asahikawa" in Koshi (formerly Yamakoshi village) have been mentioned as a representative designated landslide area. Figure 2 shows a landslide map of those areas during the Chuetsu Earthquake provided by the Geographical Survey Institute. River-clogging landslides along the Imo River during the earthquake are "Terano", "Nampei", "Naranoki",, "Higashi-takezawa" and "Junidaira", landslides from upstream (Fig. 2). Among those landslides, Terano and Higashi-takezawa were large-scale landslides, which required urgent measurements against river clogging.

Table 1 shows the number of landslides that occurred between 1949 and 2002 around Koshi. Many landslides occurred in the Asahi River basin, extending from 
Table 1. Number of landslides in Koshi (1949-2002): (a) classified by basin and (b) classified by region

(a) classified by basin

\begin{tabular}{l|c}
\hline & $\begin{array}{c}\text { Number of } \\
\text { landslides }\end{array}$ \\
\hline Asahi River & 29 \\
\hline Nanataki River & 19 \\
\hline Ohta River & 19 \\
\hline Imo River & 17 \\
\hline
\end{tabular}

Table 2. Landslides in Tanesuhara

\begin{tabular}{|c|c|c|c|c|}
\hline No. & Year & Disaster & Place & Conditions \\
\hline 1 & $\begin{array}{l}1824 \\
\text { April: } \\
\text { thawing } \\
\text { season }\end{array}$ & $\begin{array}{l}\text { Landslide } \\
\text { Length } 1.4 \mathrm{~km} \text {, } \\
\text { Width } 700 \mathrm{~m}\end{array}$ & Nakano & $\begin{array}{l}\text { Disaster throughout the } \\
\text { village. } 50 \% \text { of rice fields } \\
\text { could not be cultivated. } \\
\text { Flood induced by river } \\
\text { clogging. Two ponds of } \\
100 \mathrm{~m} \text { length and } 10 \mathrm{~m} \\
\text { depth were created. }\end{array}$ \\
\hline 2 & $\begin{array}{l}1926 \\
\text { May }\end{array}$ & $\begin{array}{l}\text { Landslide } \\
\text { Length } 1.1 \mathrm{~km} \text {, } \\
\text { Width } 180 \mathrm{~m}\end{array}$ & Nakano & $\begin{array}{l}\text { Fields and mountains of } \\
\text { more than } 2 \mathrm{~km}^{2} \text { were } \\
\text { damaged. Floods induced } \\
\text { by river clogging. }\end{array}$ \\
\hline 3 & $\begin{array}{l}1929 \\
\text { April }\end{array}$ & $\begin{array}{l}\text { Landslide } \\
\text { Width } 50 \mathrm{~m}\end{array}$ & Terano & $\begin{array}{l}\text { Prefectural route (Tochio- } \\
\text { Ojiya) was severed; } \\
\text { bridge collapsed. River } \\
\text { clogging is unclear. }\end{array}$ \\
\hline 4 & 1932 & Landslide & $\begin{array}{l}\text { Between } \\
\text { Nakano } \\
\text { and } \\
\text { Terano }\end{array}$ & $\begin{array}{l}\text { A large landslide occur- } \\
\text { red during construction } \\
\text { of landslide measures. } \\
\text { Details are unclear. }\end{array}$ \\
\hline
\end{tabular}

Mushigame, and in the Ohta River, which has Yomogihira and Nigorisawa as designated landslide areas. Although 17 landslides occurred in the Imo River basin, almost all occurred in the Tanesuhara or Nakano landslide area located upstream. Landslides were reported only slightly in Nampei, Higashi-takezawa or Junidaira, where natural dams were created as a result of the earthquake. When classified by region (Table 1(b)), the number is large in this order: Asahikawa, Tanesuhara and Mushigame.

It was reported in the Japan Landslide Society "Record of landslide disasters in Niigata (2003)" that a large landslide took place in Tochio city (Fig. 1), located in the northern part of Koshi, during a large earthquake that occurred at Takada of Joetsu city (Fig. 1) in 1751. Subsequently, this area came to be called the "Higashinakanomata landslide area" and was designated as a landslide prevention area. Although it is interesting that such a large landslide occurred at the distance of about $80 \mathrm{~km}$ from the earthquake centre, its detailed cause is unknown. According to a geological map (Takeuchi and Kato, 1994), alternation of mudstone and sandstone (mudstone dominate) of the Quaternary deposit forms this place.
The history of former Yamakoshi village is well recorded (1981). Its history from 1700 indicates Tanesuhara as the site of the greatest recorded earth-flow disaster. Table 2 shows records of landslides in Tanesuhara. The landslides are not recorded throughout the Koshi area because no such large villages existed except Tanesuhara. Although landslides in prehistoric times are unknown, the first landslide recorded in Tanesuhara occurred in 1824. An exogenous factor of landslides is snow-melt water in early spring. At that time, slopes were destroyed and two large clogging ponds were created in the Imo River. About 100 years after that event, a landslide occurred during the snow melting season at almost the same place, thereby forming a natural dam. During the Chuetsu Earthquake, which occurred about 80 years after the previous event, the river-clogging landslide was broken at Terano near Nakano. The decisive difference is that the precipitating exogenous factor was not snowmelt runoff, but an earthquake. As mentioned above, river clogging caused by landslides is a common phenomenon in the Imo River of Tanesuhara because large landslides that clog the river have occurred every century.

Concerning unrecorded landslides of prehistoric times, the landslide history of Koshi was investigated using a topographical map that was compiled using information from an aerial photograph. Figure 3 shows landslide locations during the earthquake (provided by the Geographical Survey Institute) presented on the map of old landslide topography (provided by National Research Institute for Earth Science and Disaster Prevention (NIED) and the Japan Science and Technology Agency (JST)) in the Koshi area. Many landslide configurations remain at the Imo River basin between Terano and Nakano, although it is difficult to estimate their age. Because of their geological characteristics, landslides readily occur there. According to the village history (1981), the cause of the large landslides is not rainfall or earthquake but snow-melt runoff from spring thaws. Tanesuhara and Mushigame villages were built on a site that was flattened after the landslides. Although their villages are covered by fertile landslide sediment and are presently stable, mass movements are continuing around the villages. Large-scale landslides such as those of Terano or Higashi-takezawa might be re-slide type landslides because they are located on old landslide topography (Fig. 3). Those landforms jut out as ridges and form ravines in both sides of failures (Fig. 2). Seismic motion tends to be amplified in ridges.

\section{CHARACTERISTICS OF NATURAL SLOPE FAILURE}

Many river-clogging landslides occurred along the Imo River during the earthquake. Figure 4 was prepared by overlaying the landslide locations during the earthquake on a simplified geological map provided by Takeuchi et al. (2004). Landslide designated areas obtained from a conservation map of Niigata prefecture (1982) are also 


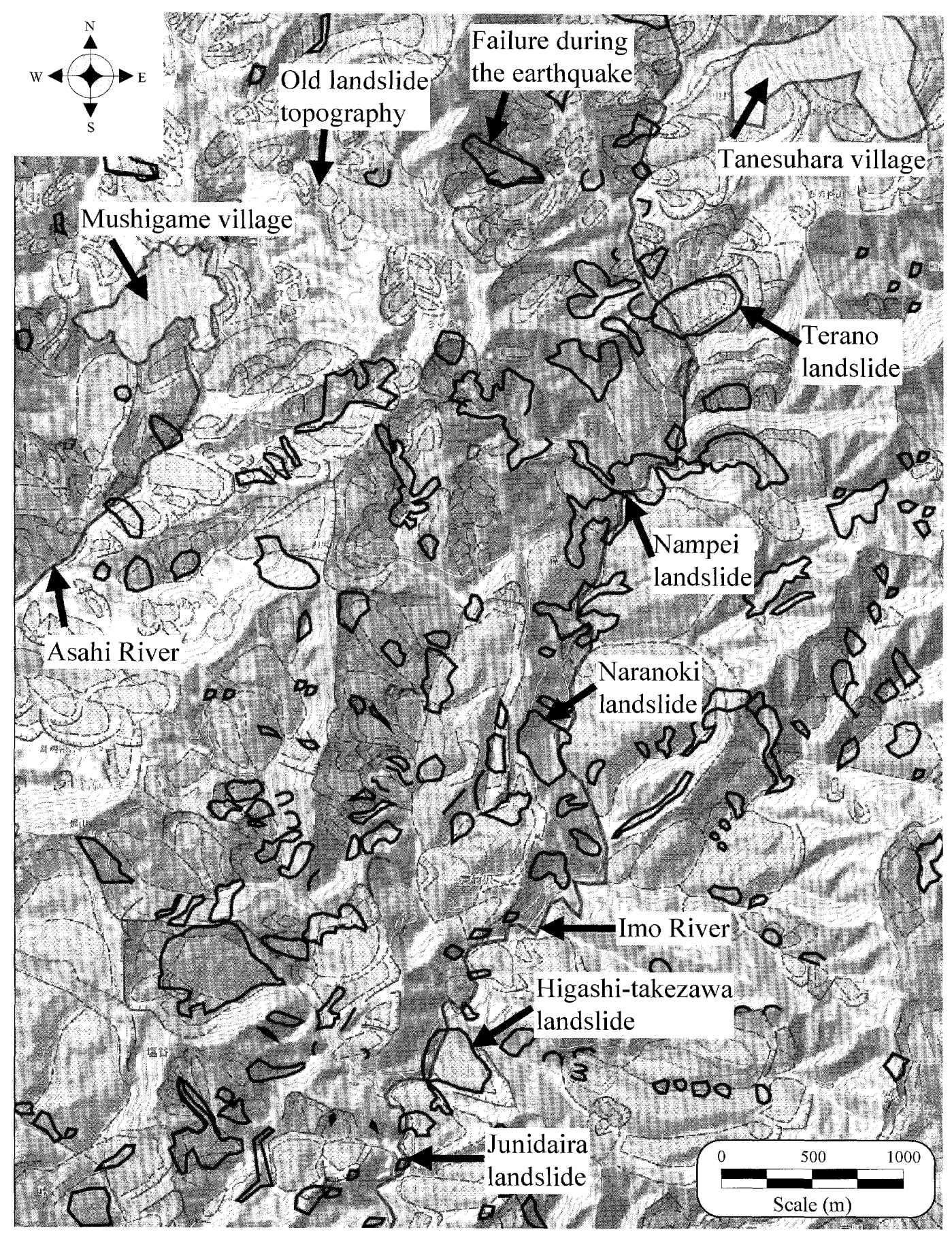

Fig. 3. Landslide map of Koshi (provided by NIED and JST)

indicated in the figure.

The west side of the map, including Mushigame, which is classified in the Asahi River basin (Fig. 4), is geologically an Araya deposit that is massive dark grey mudstone. Shifting toward the east side of the map, which is classified in the Imo River basin (Fig. 4), the deposit changes to alternation of sandstone and mudstone named Kawaguchi and Wanatsu deposits. Alternation of sandstone and mudstone is distributed mainly along the Imo River, except in its upper course. As shown in Fig. 4, numerous landslides occurred during the earthquake in areas with alternated layers of sandstone and mudstone compared with massive mudstone deposits. This finding engenders the conclusion that sandy natural slopes are more fragile than clayey natural slopes during earthquakes. On the other hand, landslide-designated areas are distributed mainly in the massive mudstone deposits, indicating that the failure mechanisms of landslides induced by earthquakes differ from those induced by snow-melt waters.

Moreover, the notable geological features of this region are syncline and anticline structures. They form a complex topography in which synclinal axes and anticlinal axes are arranged with a short interval (Fig. 4). For that reason a peculiarly cuesta topography appears in this region. Fragile and weak slopes are therefore easily 


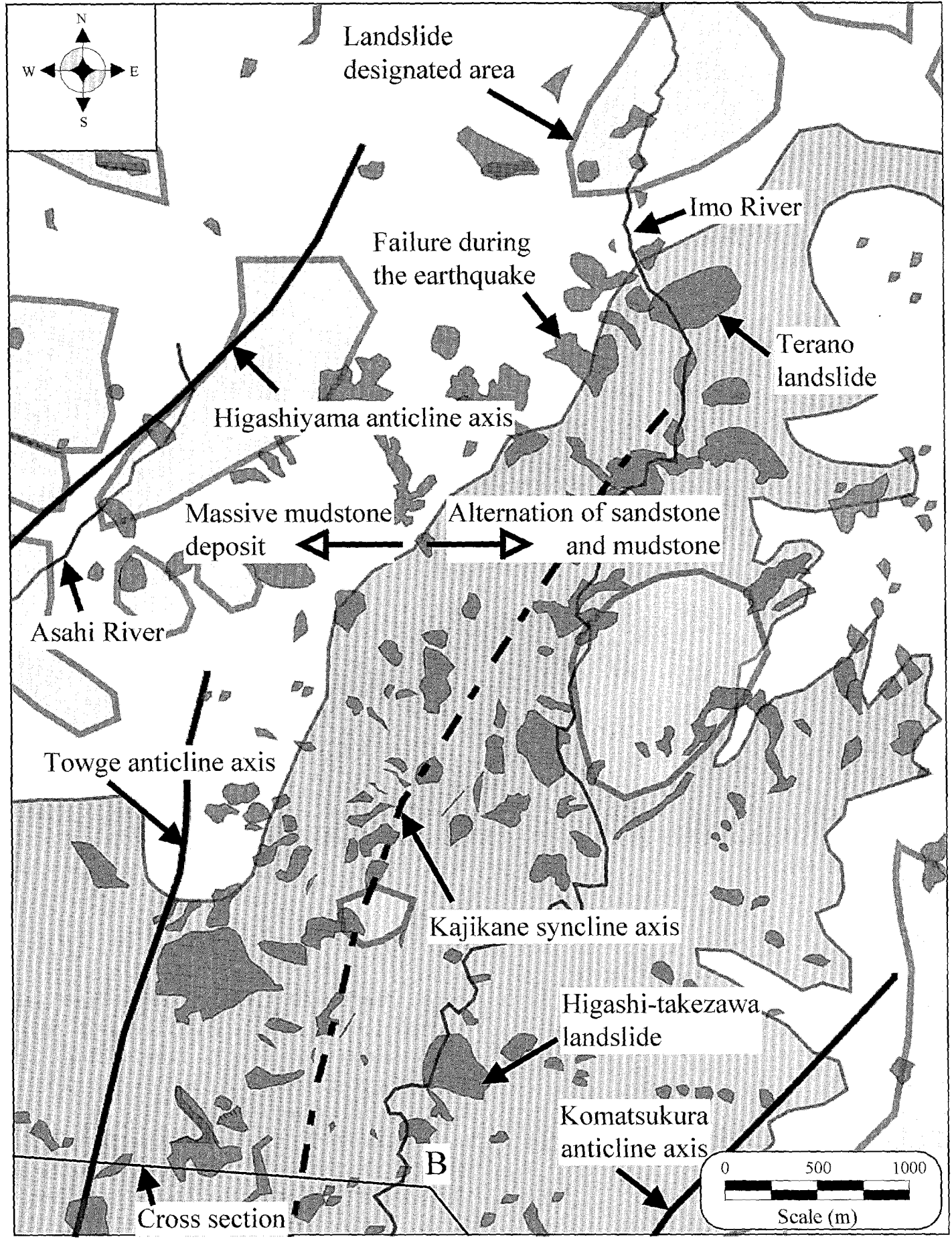

Fig. 4. Landslide distribution and geological map of Koshi

formed. In addition, the river scrapes away the ground surface and the slope toe becomes unstable. Those reasons explain the numerous landslides that occurred during this earthquake.

Figure 5 shows a geological cross section of the area south of former Yamakoshi village (Junidaira) published by Geological Survey of Japan. The location of this sampled geological area is shown in Fig. 4. Sandstone (W) and sandy mudstone $\left(\mathrm{S}, \mathrm{Ku}_{2}\right)$ are distributed widely around the Imo River. This is a representative folded mountains area composed of syncline and anticline. Geological cross sections clarify that a dip slope appears in the left bank of the Imo River and a reverse-dip slope on the right bank of the river.

Photo 1 shows landslides that caused clogging of the Imo River. Terano is located southwest of Tanesuhara. The natural slope moved at the left bank of the Imo River (Photo 1(a)). That about 360-m-long slide was $200 \mathrm{~m}$ and $290 \mathrm{~m}$ wide in its upper and lower parts, respectively. The inclination before failure was about $17^{\circ}$. The depth is about $20 \mathrm{~m}$ in the deep part, although it is not clearly discernible. Soft sandy soil, which was extracted for physical tests, was widely distributed in the main scarp. Temporary drainage measures against river clogging were 


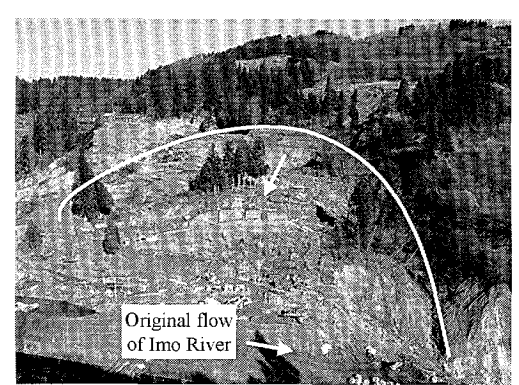

(a) Terano (Left bank)

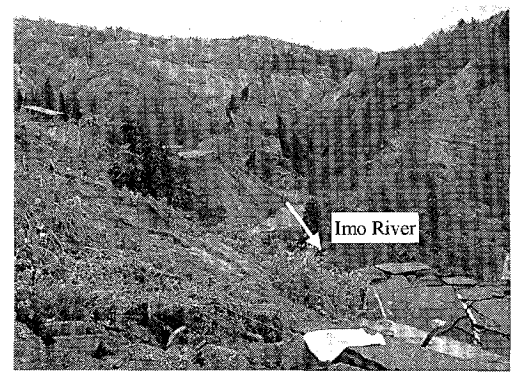

(d) Nampai

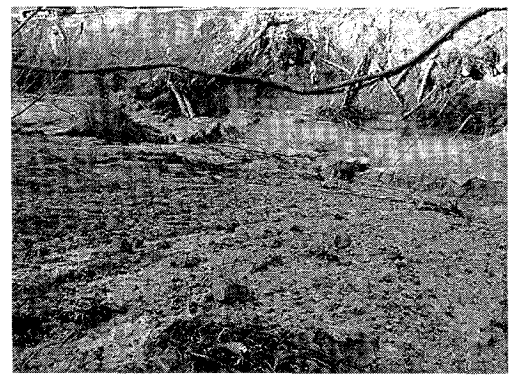

(g) Smooth siltstone

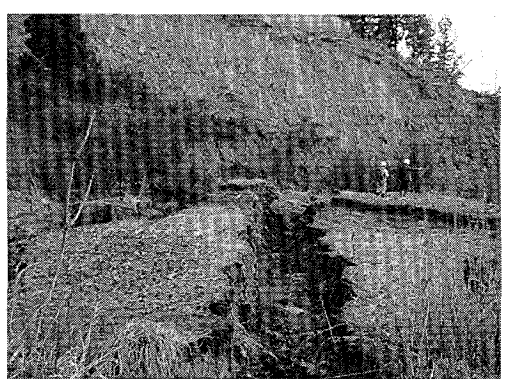

(b) Upper part of the slope

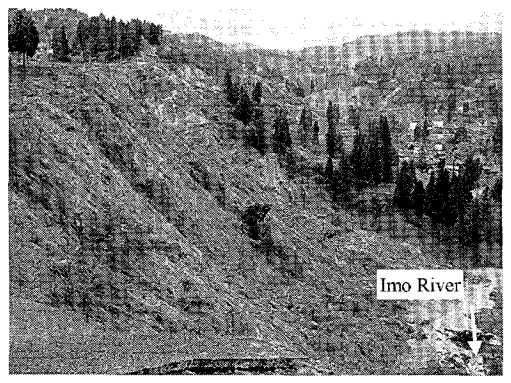

(e) Naranoki

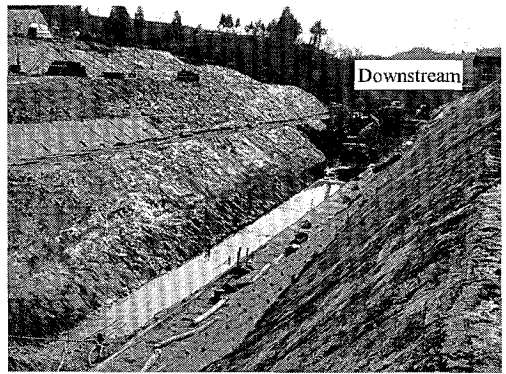

(h) Temporary watercourse

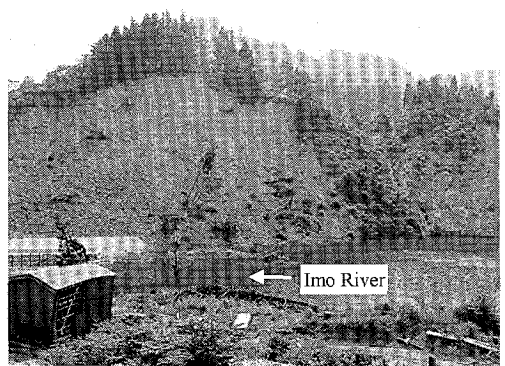

(c) Terano (Right bank)

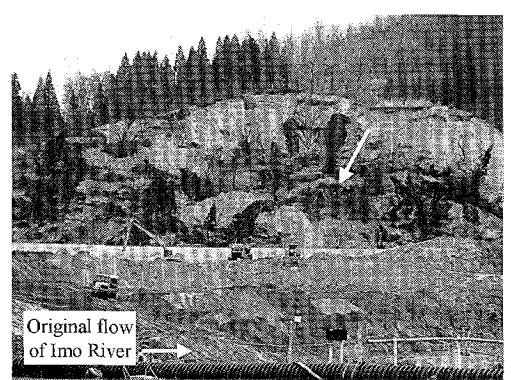

(f) Higashi-takezawa

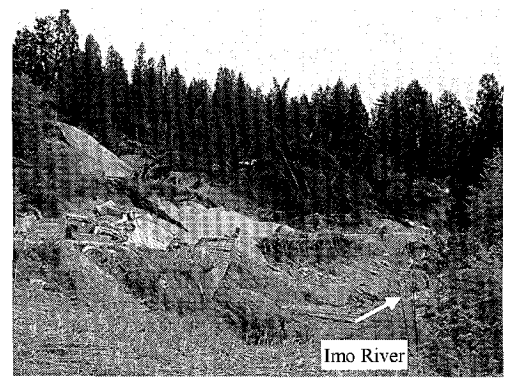

(i) Junidaira

Photo 1. Landslides clogged the Imo River

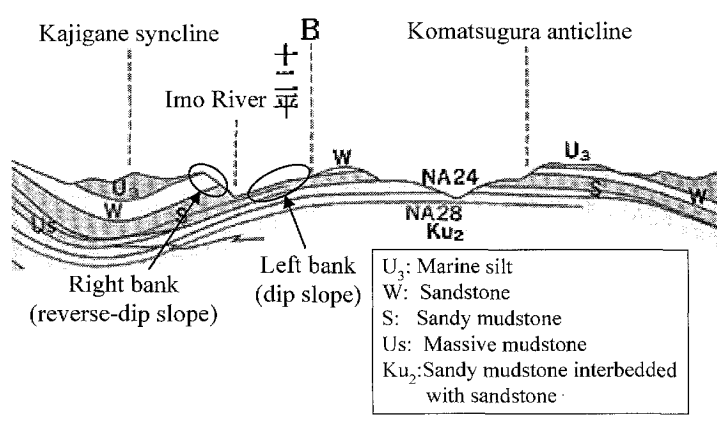

Fig. 5. Geological cross section of the south of former Yamakoshi village published by National Institute of Advanced Industrial Science and Technology (AIST)

conducted immediately to prevent failure of the natural dam. The slip mass corresponds to an old landslide trace shown in Fig. 3; small valleys are present on both sides of the failure mass. Groundwater is apparently abundant in this area: ponds are visible in the upper part of the slope (Photo 1(b)). One witness insisted that this landslide had occurred not during the main shock but rather during the aftershock. The ground was probably disturbed by the main shock and became weak. Other salient features include several surface failures that occurred in the right bank, which is a reverse-dip slope (Photo 1(c)). However, the amount of sediment that flowed into the river is small because of surface failures.

Nampei is about $1 \mathrm{~km}$ downstream from Terano. The steep slope is about $35^{\circ}$ and a few hundred meters wide; it was collapsed at both banks of the Imo River (Photo 1(d)). Urgent measures against river clogging were unnecessary because of surface failure of only a few meters' depth.

A slope of about $30^{\circ}, 420 \mathrm{~m}$ wide and about $200 \mathrm{~m}$ long had collapsed at the right bank of the Imo River in Naranoki (Photo 1(e)). Although the depth of this slide is larger than that in Nampai, it would be classified as a surface failure. The soil that appeared on the bedrock in the failure area was soft sandy soil. Sampling was carried out for physical and shear tests. The properties of the soil samples are discussed later.

The soil mass, which is $220 \mathrm{~m}$ and $340 \mathrm{~m}$ wide in upper and lower parts, respectively, and $340 \mathrm{~m}$ long, moved about $70 \mathrm{~m}$ during the earthquake at Higashi-takezawa, which is at the confluence of the Imo and Maesawa Rivers. Photo 1(f) shows the main scarp of the landslide. 
The main scarp sediment was poorly graded sand, which was extracted for physical tests. At the failure point, the photo shows that ground preparations, as a measure against river clogging, had already been conducted. The failure slope is the left bank of the Imo River; it has a gentle $15^{\circ}$ ridge, which is about $21^{\circ}$ inside of the slide. Smooth mudstone, whose colour is subdued blue, appears in the lower part of the main scarp (Photo 1(g)). The smooth mudstone is inclined about $18^{\circ}$. The mudstone sample was also acquired to obtain physical properties. The mass movement corresponds with an old

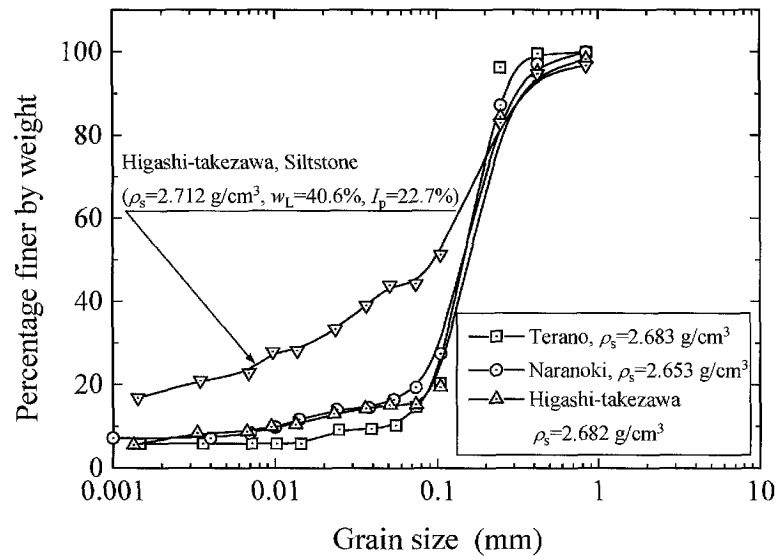

Fig. 6. Grain size distribution obtained from failure areas along the Imo River

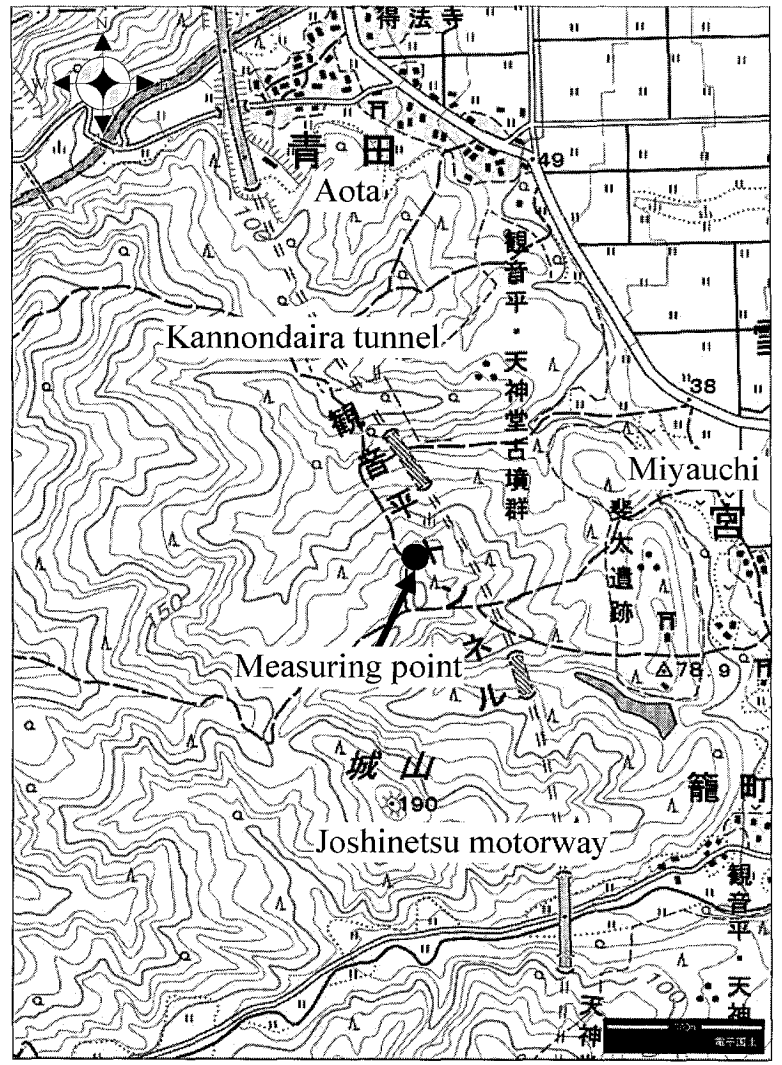

(a) Miyauchi of Myoko city landslide trace in Fig. 3. Small valleys exist on both sides of the failure mass, just as in Terano's case. A temporary drainage channel is constructed with installation of a drainage pump to prevent the natural dam from seepage failure or erosion caused by overflow (Photo 1(h)).

Slope failures occurred on both banks of the Imo River in the Junidaira area, but they were not large. Photo 1(i) shows a landslide at the left bank of the dip slope. The slope was gentle: less than $20^{\circ}$. It seems to be a deeper slide than a mere surface failure because avalanchemitigating facilities and trees are moved just as they are. This slope is continuing from Higashi-takezawa; topographical information suggests the possibility that a large landslide like Higashi-takezawa might occur.

Peculiar slope failures occurred at the right and left banks of the Imo River. Surface failures occurred frequently at the right bank having reverse-dip slope strata, whereas problematical large landslides occurred occasionally at the left bank, which is a dip gentle slope.

Figure 6 shows the grain size distribution arising from the failure area along the Imo River. All samples from the main scarps are sand including less than $10 \%$ fines. This means that sandy natural slopes are more fragile than clayey natural slopes during earthquakes. The density of Naranoki soil particles is slightly less than those of other locations. The exposed smooth mudstone at Higashitakezawa is composed mainly of silt; that is, siltstone. These results agree with information from the geological

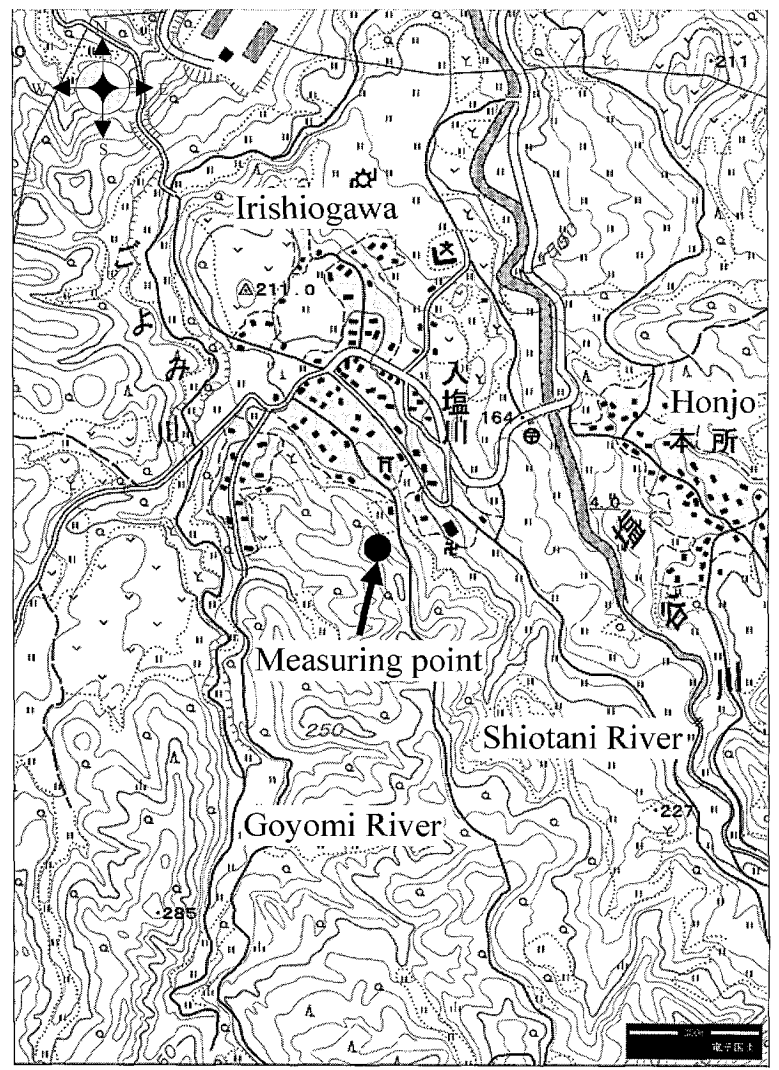

(b) Irishiogawa of Tochio city

Fig. 7. Topographical map around the pore water pressure measuring points (provided by Geographical Survey Institute) 


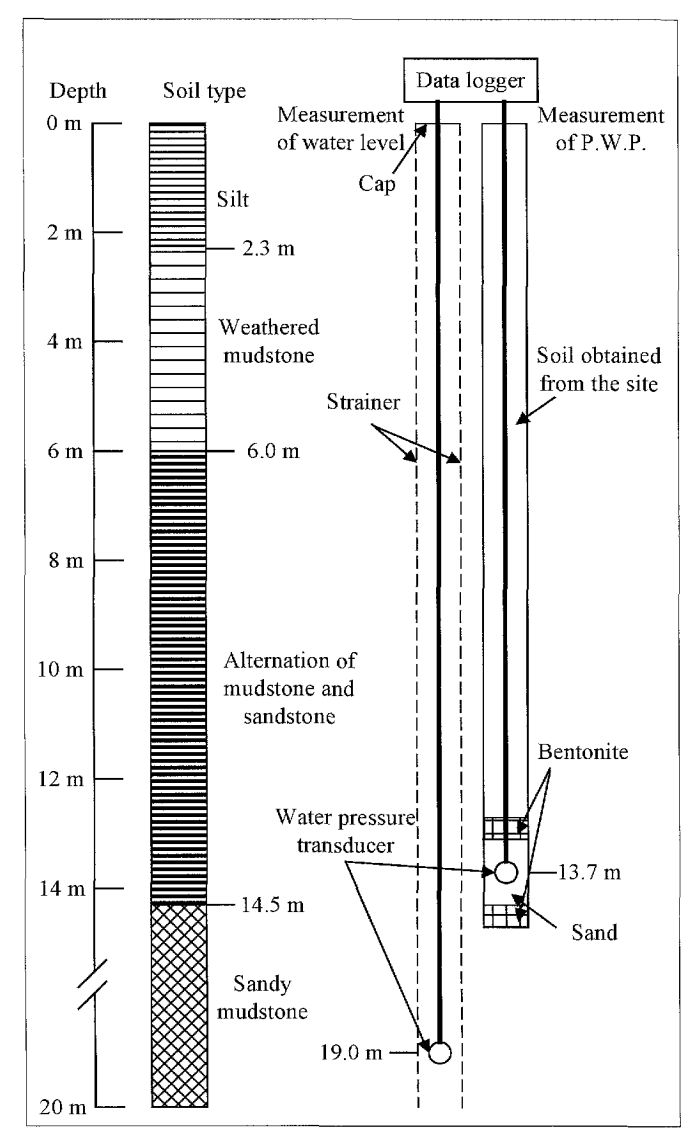

(a) Miyauchi of Myoko city

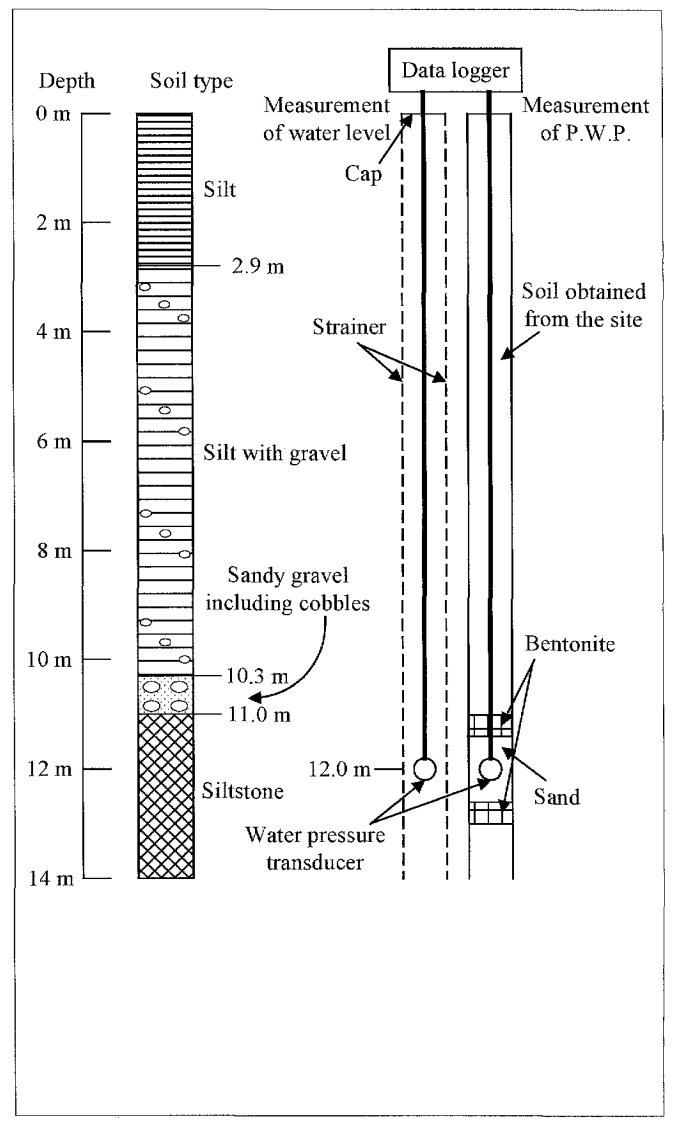

(b) Irishiogawa of Tochio city

Fig. 8. Depth of sensors and soil profiles

map, which shows alternation of sandstone and mudstone strata.

\section{MEASUREMENT OF WATER PRESSURE IN PREVIOUS LANDSLIDE AREAS}

Water level and pore water pressure have been measured by our laboratory since 1995 in old landslide areas. Figure 7 shows a topographical map around the measuring points at Miyauchi of Myoko city (Fig. 7(a)) and Irishiogawa of Tochio city (Fig. 7(b)). Those locations in Niigata prefecture are shown in Fig. 1. The observation points are inferred to be the upper parts of the landslides. The measuring point of Miyauchi is located next to the Joshinetsu motorway. When the motorway tunnel was constructed, the natural slope was cut and the slope protection works such as drainage system on the surface or a planting treatment were carried out. In Irishiogawa, numerous infiltration wells were installed because it is an old landslide area (Toyota et al., 2006). Mass movements in both areas induced by the earthquake are not obvious because the slope deformation had not been measured; deformation was not confirmed by visual observation of those slopes.

Figures 8(a) and 8(b) respectively show the depth of ground-installed water pressure sensors and their geologic column of Miyauchi and Irishiogawa. A borehole with
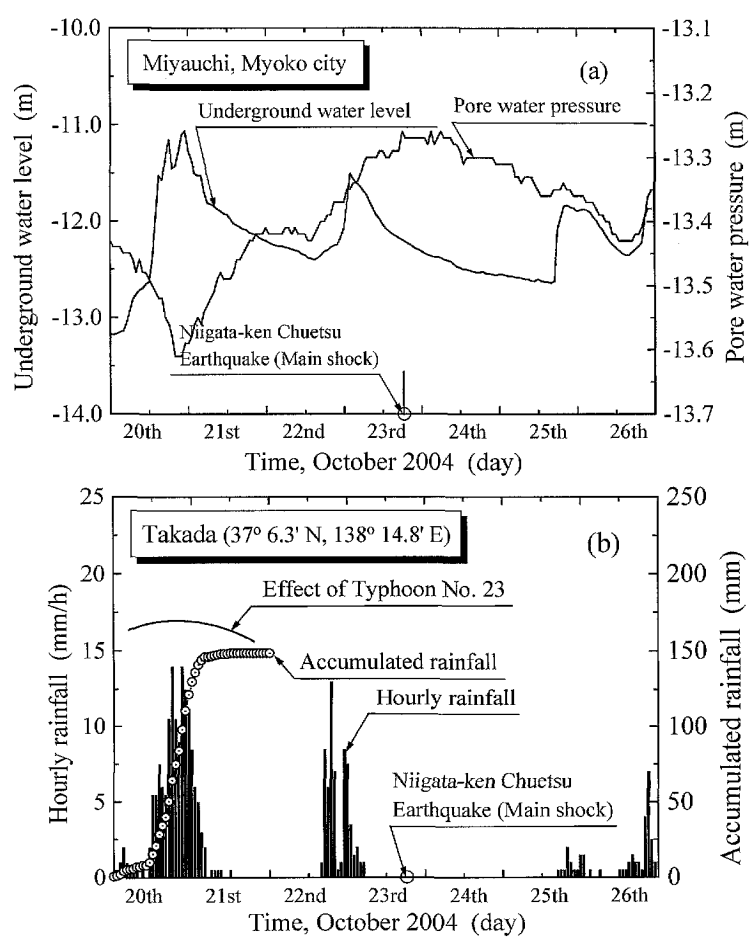

Fig. 9. Records of water pressure and hourly rainfall during the earthquake at Miyauchi of Myoko city 

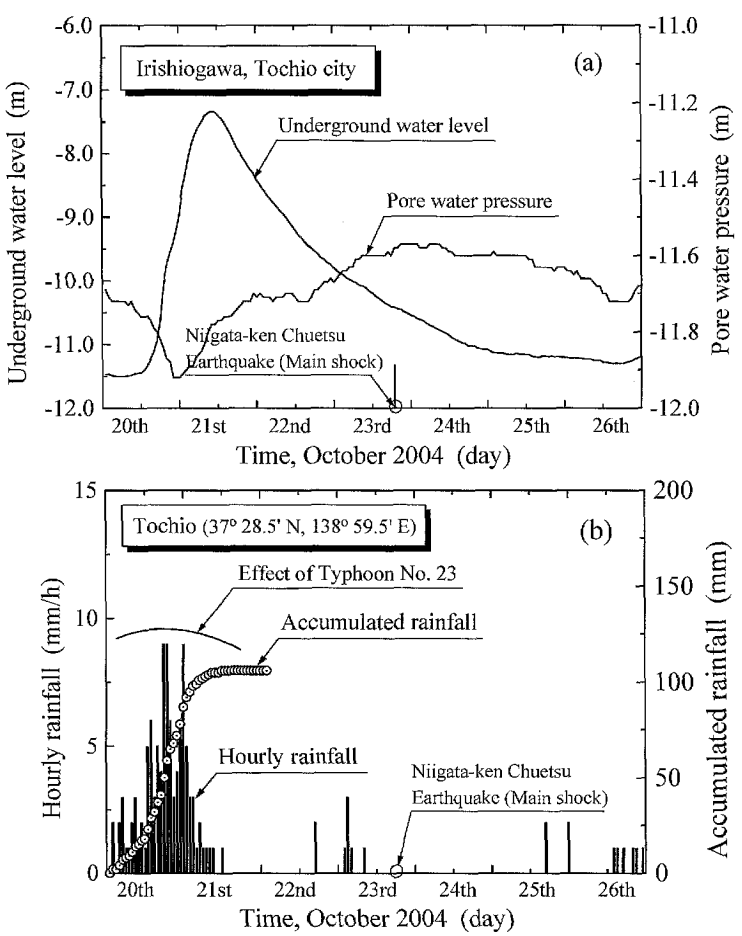

Fig. 10. Records of water pressure and hourly rainfall during the earthquake at Irishiogawa of Tochio city

a strainer was used for groundwater level measurements. For pore water pressure measurement, water pressure transducers in a borehole were buried in sand. Their upper and lower sides were sealed with bentonite, as shown in Fig. 8. The boreholes for pore water pressure measurement are buried completely using soils obtained from the site.

Figures 9 and 10 respectively show the records of water pressure and hourly rainfall at Miyauchi and Irishiogawa. The values of water pressure have been acquired using a data logger on the hour. This means that the water pressures were measured after 4 minutes from the main shock because the earthquake occurred at 17:56. The rainfall data of the nearest areas from our measuring points were selected from among data provided by the Japan Meteorological Agency. The measuring points of Miyauchi and Irishiogawa are about $6 \mathrm{~km}$ and $4 \mathrm{~km}$ apart from the rainfall-recorded points, respectively. Rainfall occurred by typhoon No. 23 of 20 Oct. 2004. The accumulated rainfall reached $100 \mathrm{~mm}$ in those areas (Figs. 9(b) and 10(b)). The groundwater level rose quickly with the rainfall: about $2 \mathrm{~m}$ in Miyauchi and $4 \mathrm{~m}$ in Irishiogawa. The difference in the rise of groundwater between Miyauchi and Irishiogawa is considered to result from their geological and topographical features. These areas are inferred to be catchment areas because elevated underground water levels descend gradually over a few days. The rise in groundwater table induced by the typhoon had dropped by about $1 \mathrm{~m}$ in Miyauchi and $3 \mathrm{~m}$ in Irishiogawa by the time of the Niigata-ken Chuetsu Earthquake. Similar behaviour was observed concerning the pore water pressure at both areas: the pore water
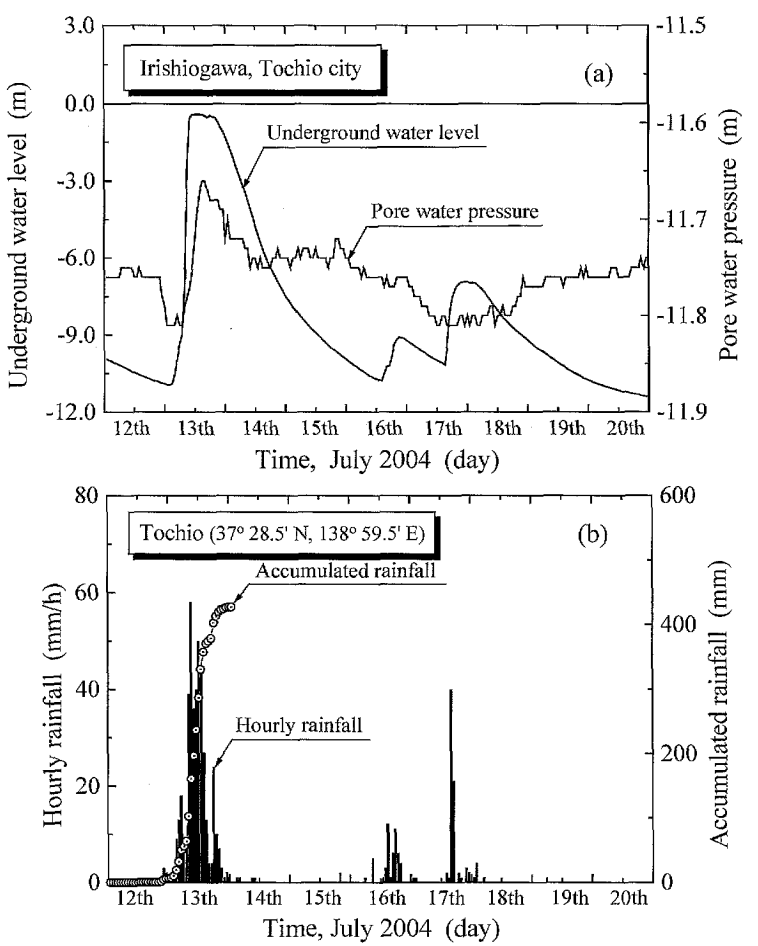

Fig. 11. Records of water pressure and hourly rainfall during the heavy rainfall disaster in Niigata on 13 July 2004 at Irishiogawa of Tochio city

pressure dropped on 20 Oct. 2004 with low atmospheric pressure; it then increased gradually. Although the pore water pressure reached a peak at the time of Niigata-ken Chuetsu Earthquake, the pore water pressure increase of about $20 \mathrm{~cm}$ in the water head is too small to affect slope failure. The pore water pressure sensors might not be installed near the slip surface where pore water pressure will change most during a certain event. It seems that there was considerable rainfall on the night before the earthquake at Miyauchi (Fig. 9(b)).

As additional information for comparison, the records of Irishiogawa during the heavy rainfall disaster in Niigata on 13 July 2004 (Toyota et al., 2006) are presented in Fig. 11. Unfortunately, data of Miyauchi during this event were unobtainable. The total amount of rainfall reached $400 \mathrm{~mm}$ and the groundwater level rose no less than $10 \mathrm{~m}$. Nevertheless, the pore water pressure increased only dozens of centimetres in the water head. Those results underscore the possibility that pore water pressures were measured at strata where excess pore water pressure is not generated sensitively.

\section{SOIL PROPERTIES OBTAINED FROM A NATURAL SLOPE FAILURE SITE}

Soil properties obtained from the slope failure at Naranoki (Photo 1(e)) were examined in detail. Block samples were obtained from the site of the failure (Photo 2(a)) and trimmed to make specimens for triaxial and direct (box) shear tests in the laboratory (Photo 2(b)). The specimens were extracted laterally from the soil block. Therefore, the direction of compression in triaxial 

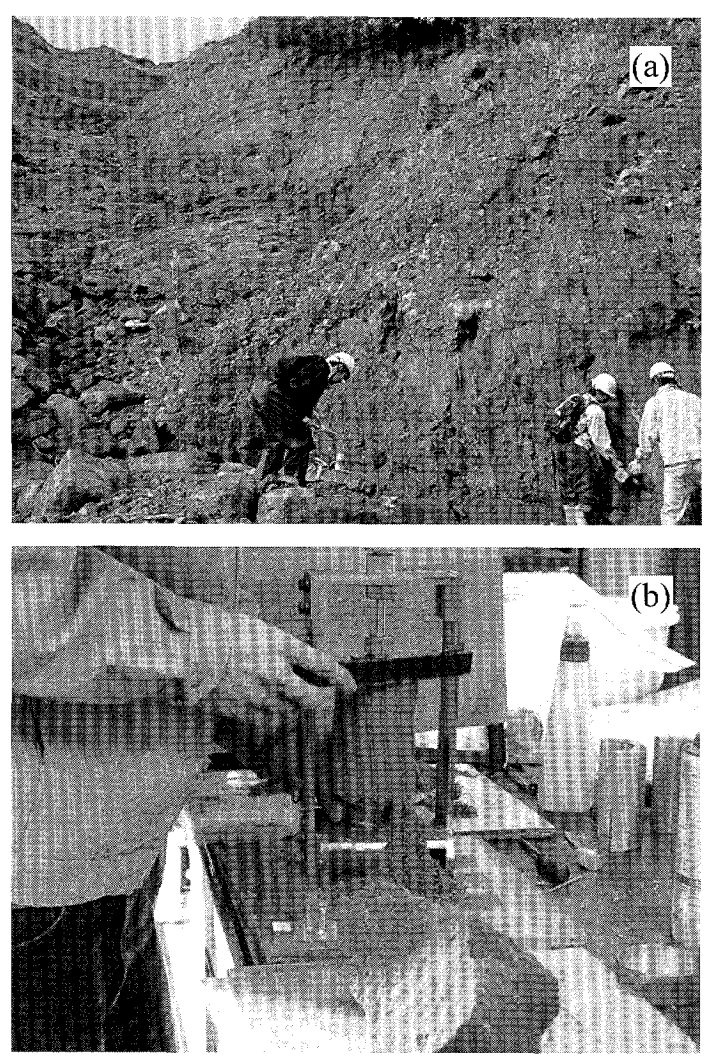

Photo 2. Soil sampling at the Naranoki failure area: (a) sampling point and (b) trimming for triaxial tests

tests becomes a horizontal plane in the ground. The soil is very soft and can be easily broken and shaped by hand. The grain size distribution of the soil is shown in Fig. 6. Specimens were $d=50 \mathrm{~mm}$ in diameter and $h=100 \mathrm{~mm}$ in height in triaxial tests, and $d=60 \mathrm{~mm}$ and $h=20 \mathrm{~mm}$ in direct (box) shear tests. The specimens were saturated using the vacuum saturation procedure. Drained triaxial compression tests were performed under constant $p^{\prime}$ conditions with axial strain rates of $0.02 \% / \mathrm{min}$; direct shear tests were conducted under constant pressure with shear rates of $0.02 \mathrm{~mm} / \mathrm{min}$. There were two types of density in nearby similar layers: one was dense $(e=0.69)$ and the other was medium dense $(e=0.85)$. The maximum and minimum void ratios based on Japanese Industrial Standards (JIS A 1224) were 1.207 and 0.676 , respectively. It is noteworthy that the soil is beyond the standard's application because it contains about 10\% fines.

Figures 12 and 13 respectively show the shear behaviour of undisturbed specimens in triaxial and direct shear tests. Direct shear tests were performed only in medium dense specimens. In the case of dense sand, peaks are clearly apparent in stress-strain relationships (Fig. 12(a)) and dilative behaviours occur, as shown in Fig. 12(b). In contrast, peaks of medium dense sand are indistinct (Fig. 12(a)) and contractive behaviours appear at the small shear-strain region of large confining-stress $\left(p^{\prime}=\right.$ $200 \mathrm{kPa}$ ) case (Fig. 12(b)). The void ratios and shear behaviours indicate that the dense Naranoki sand is extremely dense. At the ultimate state after the peak in the stress-strain relationships, the ultimate strengths of
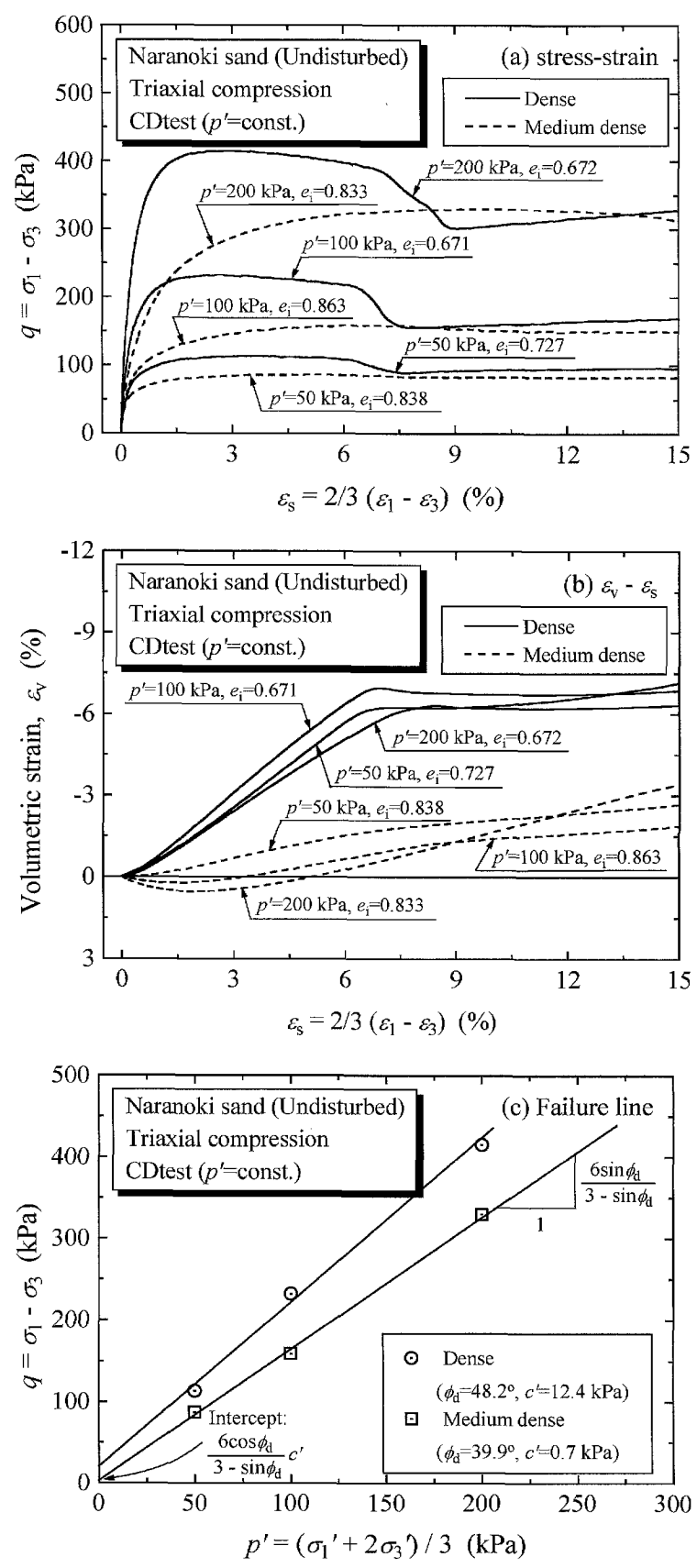

Fig. 12. Shear behaviour of samples obtained from Naranoki in triaxial compression tests

dense sands agree roughly with those of medium dense ones. This indicates that dense and medium dense sands possess mutually similar physical properties. With regard to results of direct shear tests, behaviour resembles that of medium dense sand of triaxial tests (Figs. 13(a) and 13(b)).

Figures 12(c) and 13(c) show failure lines obtained respectively from triaxial and direct shear tests. The dense sand has a much larger angle of shear resistance, $\phi_{\mathrm{d}}$, and cohesion, $c^{\prime}$, than the medium dense sand (Fig. 12(c)). Regarding the medium dense sand, although the angle of shear resistance, $\phi_{\mathrm{d}}$, that is obtained from the triaxial tests is greater than that from direct shear tests, cohesion, $c^{\prime}$, from the triaxial tests is less than that from direct 

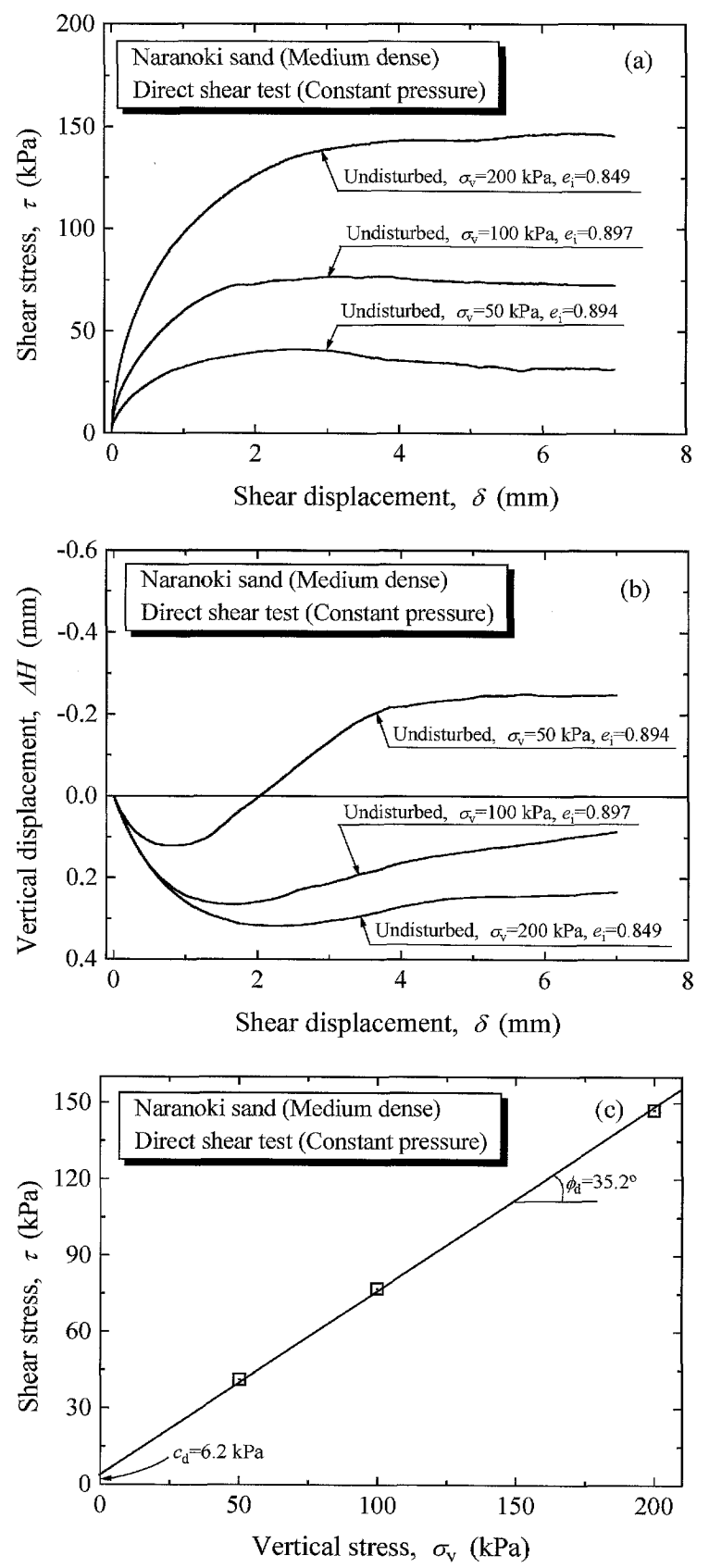

Fig. 13. Shear behaviour of samples obtained from Naranoki in direct shear tests

shear tests. Those differences pertain because the strength parameters, $\phi_{\mathrm{d}}$ and $c^{\prime}$, vary subtly with even small scattering data. The cohesions are very small in both tests. Therefore the cementation and ageing effects of medium dense Naranoki sand layer are small. Those results imply that failure would occur in the medium dense sand layer because the strength of the dense Naranoki sand is much greater than that of medium dense sand.

The medium dense layer is considered to be more important for failure than the dense one. Reconstituted specimens were prepared as medium dense $(e=0.85)$ using the moist tamping (MT) method to elucidate the unsaturated soil shear behaviour of medium dense specimens. By MT method, the soil, which has a water content

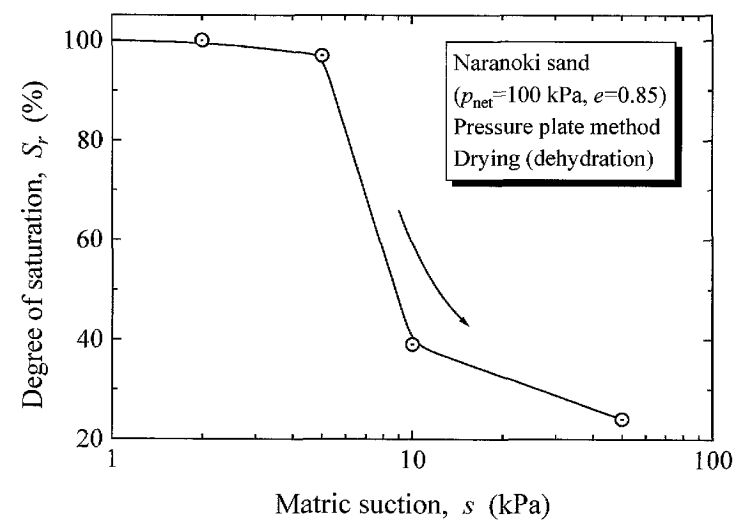

Fig. 14. Soil-water characteristic curve of sample obtained from Naranoki

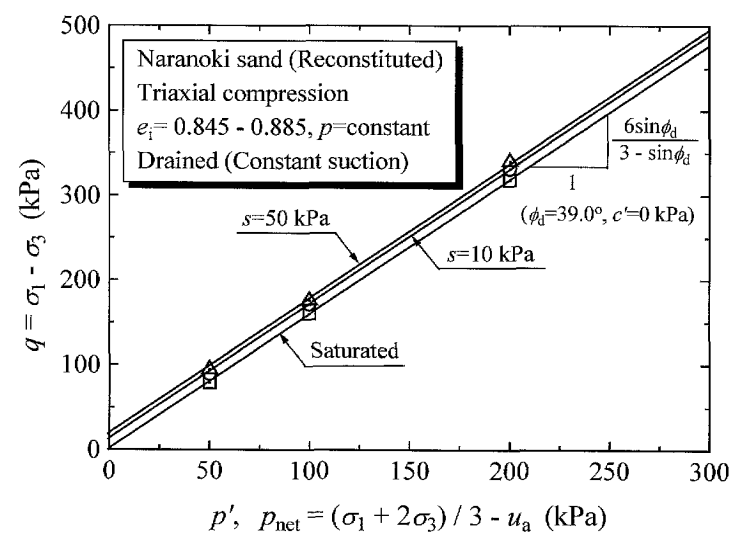

Fig. 15. Failure lines of unsaturated medium dense Naranoki sand

of $10 \%$, was placed in a 5 -cm-diameter mould and tamped carefully at $1 \mathrm{~cm}$ layers using a 2 -cm-diameter rod to control the specimen density. The drying portion of the soil-water characteristic curve obtained from the pressure plate method is shown in Fig. 14. The experiment was carried out under net mean principal stress, $p_{\text {net }}=100 \mathrm{kPa}$, using triaxial apparatus. This result suggests that the air entry value of the soil is approximately $5-10 \mathrm{kPa}$. The degree of saturation dramatically decreases at the air entry value because of the sandy soil specimen. Therefore, when the soil is under stable conditions, the soil is in either fully saturated or in a low degree of saturation.

Shear properties under an unsaturated state were also examined, where suction was controlled by the pressure plate method using a ceramic disc. Drained (constant suction, $s$ ) triaxial compression tests were performed under constant $p^{\prime}$ conditions, with axial strain rates of $0.01 \% / \mathrm{min}$ using reconstituted medium dense Naranoki sand. Figure 15 shows failure lines of the unsaturated specimens. Under saturated state, strength parameters of reconstituted specimens, $\phi_{\mathrm{d}}=39.0^{\circ}$ and $c^{\prime}=0 \mathrm{kPa}$ shown in Fig. 15, are almost the same as those of undisturbed specimens, $\phi_{\mathrm{d}}=39.9^{\circ}$ and $c^{\prime}=0.7 \mathrm{kPa}$ in Fig. 12. Reconstituted specimens having similar strength with that of 
undisturbed ones could be reproduced by using MT method to make the specimens the same void ratio with undisturbed ones. Failure lines of different suctions are approximately parallel to that of saturated soil. Cohesion is greater when the matric suction is larger. Although the cohesion changes to some degree between saturated and $s=10 \mathrm{kPa}$, small differences exist between $s=10 \mathrm{kPa}$ and $s=50 \mathrm{kPa}$ because the tested conditions $(s=10 \mathrm{kPa}$ and $s=50 \mathrm{kPa})$ are a part of the soil-water characteristic curve where little difference exists in the degree of saturation with suction. The result shows that the strength increase induced by matric suction cannot be expected enough. Concerning the external force, the slope at Naranoki is steep, which is about $30^{\circ}$, and is located near the epicentre. It is considered that large shear stress, which consists of static shear stress by the slope and dynamic shear stress induced by the inertia force, was acting in the slope during the earthquake. This slope is supposed to be fragile and unstable during the earthquake because the soil possesses only small cohesion in spite of the large external force induced by the slope and the seismic motions. For example, for this estimation, Tsujioka (2006) performed stability analysis based on a slice method where moisture and seismic force effects on soils were considered.

\section{CONCLUSIONS}

The Niigata-ken Chuetsu Earthquake caused heavy damage to infrastructure in hilly and mountainous areas. Soil masses of landslides clogged river channels and produced natural dams. Effects of geographical and geological features, such as folding, were apparent. The matter of natural dams developed into a social problem because towns were submerged and all residents of former Yamakoshi village fled their homes. Moreover, residents of downstream areas were also exposed to danger of debris flow caused by the collapse of natural dams. A detailed investigation was carried out on landslides along the Imo River to clarify the failure mechanisms.

Main findings from the study are summarised as:

1. Large-scale landslides during the Niigata-ken Chuetsu Earthquake are regarded as re-slide type landslides because they occurred on old landslide traces.

2. The greater part of slope failures during the earthquake occurred at alternating sandstone and mudstone strata, but landslides, which moved gradually during snow melting season, have usually occurred at massive mudstone of quaternary and tertiary deposits.

3. During earthquakes, surface failures occurred easily at steep reverse-dip slopes, whereas large landslides occurred at gentle dip slopes.

4. The groundwater table was raised by about $2 \mathrm{~m}$ in
Miyauchi and $4 \mathrm{~m}$ in Irishiogawa, which are old landslide area, by typhoon No. 23. But the rise in groundwater table had dropped by about $1 \mathrm{~m}$ in Miyauchi and $3 \mathrm{~m}$ in Irishiogawa by the time of the Niigata-ken Chuetsu Earthquake.

5. Very dense and medium dense sand layers were involved in the Naranoki slope failure. The very dense sand had much larger strength than that of the medium dense sand, although the ultimate strengths of both sands were similar. Therefore it is supposed that the failure was triggered in the medium dense sand layer.

6. The air entry value of the medium dense Naranoki sand is approximately $5-10 \mathrm{kPa}$. The apparent cohesion of sand, induced by drying, is no more than about $10 \mathrm{kPa}$; furthermore, the cementation and ageing effects of Naranoki sand layer are small. From these facts, the Naranoki slope is inferred to be fragile during an earthquake.

\section{ACKNOWLEDGEMENTS}

We investigated the stricken area with many researchers and obtained useful information. Soil tests were conducted with the assistance of students from the Geotechnical Engineering Laboratory, the Department of Civil and Environmental Engineering, Nagaoka University of Technology. The authors express sincere appreciation for their contributions to this study.

\section{REFERENCES}

1) Editorial Committee of History of Yamakoshi village (1981): History of Yamakoshi Village (in Japanese).

2) Geographical Survey Institute (2004): Disaster Map of Niigata-ken Chuetsu Earthquake (http://zgate.gsi.go.jp/niigatajishin/index. $\mathrm{htm})$.

3) Japan Society of Civil Engineers (2006): Report on the 2004 Niigata Chuetsu Earthquake, JSCE, CD Rom (in Japanese).

4) National Research Institute for Earth Science and Disaster Prevention (NIED) and Japan Science and Technology Agency (JST) (2004): Landslide Map (http://1sweb1.ess.bosai.go.jp/jisuberi/ jisuberi_mini/jisuberi_top.html).

5) Niigata Branch of the Japan Landslide Society (2003): Record of Landslide Disasters in Niigata, CD Rom (in Japanese).

6) Niigata prefecture (1982): Conservation Map (in Japanese).

7) Takeuchi, K. and Kato, S. (1994): 1:50,000 Geological Map of the Takada-Tobu Region, Geological Survey of Japan.

8) Takeuchi, K., Yanagisawa, Y., Miyazaki, J. and Ozaki, M. (2004): 1:50,000 Digital Geological Map of the Uonuma Region, Niigata Prefecture (Ver. 1), GSJ Open-file Report, No. 412 (http://www. gsj.jp/GDB/openfile/files/no0412/index.html).

9) Toyota, H., Nakamura, K. and Sakai, N. (2006): Evaluation of dike and natural slope failure induced by heavy rainfall in Niigata on 13 July 2004, Soils and Foundations, 46(1), 83-98, 2006.

10) Tsujioka, T. (2006): Strength evaluation of unsaturated slopes during heavy rainfalls and earthquakes, Master Thesis, Nagaoka University of Technology (in Japanese).

11) Yanagisawa, Y., Kobayashi, I., Takeuchi, K., Tateishi, M., Chihara, K. and Kato, S. (1986): 1:50,000 Geological Map of the Ojiya Region, Geological Survey of Japan. 